\title{
THE EFFECT OF OILING THE COTTON ON THE AIRBORNE CONTAMINATION IN CARD ROOMS \\ BY
}

\author{
D. G. DRUMMOND, MARY HAMLIN, J. K. DONOGHUE, and F. BROWNSETT \\ From the Shirley Institute, The British Cotton Industry Research Association, Didsbury, Manchester
}

(RECEIVED FOR PUBLICATION JULY 20, 1953)

A disabling chest disease characterized by bronchospasm (" byssinosis") has, for many years, been recognized as affecting the workers in cotton blow rooms and card rooms (Collis, 1909), and has been attributed to inhalation of the airborne dust round the machines. It remains a serious industrial hazard in spite of measures which have been taken to reduce the dust, such as the improvement of ventilation in the mills and the use of vacuum instead of open stripping-brushes on the carding machines.

More recently, however, there has been coming into use a method of dust suppression by spraying an oil emulsion on to the cotton at an early stage of processing (Paton, 1948), and the Factory Inspection Department has reported an impression that the health of the card-room operatives has improved in those mills which have introduced "oiling" the cotton. We have therefore taken an opportunity of making quantitative measurements of the airborne material in the card rooms of a group of mills before and after oiling had been installed.

Any improvement in atmospheric cleanliness due to oiling the cotton must, of course, be considered in relation to its possible disadvantages. These may be classed under three headings : (1) difficulties of maintenance of the oiling equipment, (2) interference by the oil with the subsequent processing, and (3) interference with final yarn quality.

If the oiling equipment is properly designed and operated none of these factors should prove so serious as to prohibit the use of oiling, but a full discussion of this is outside the scope of the present paper.

The dust load in the air of a card room includes at least four distinguishable components: (1) short pieces of broken fibre, known collectively as " fly ", which is responsible for the major part of the visible cloud of dust ; (2) fine dust particles from, say, $10 \mu$ down to submicroscopic sizes, probably derived mainly from the dried plant tissue debris or " trash" which passes through the machines with the cotton (Fig. 1); (3) bacteria, which are mainly soil and water organisms from the cotton fields and are present in extraordinarily large numbers in the card-room air; and (4) fungal spores and hyphae of which numbers are large, but in no way comparable with those of the bacteria.

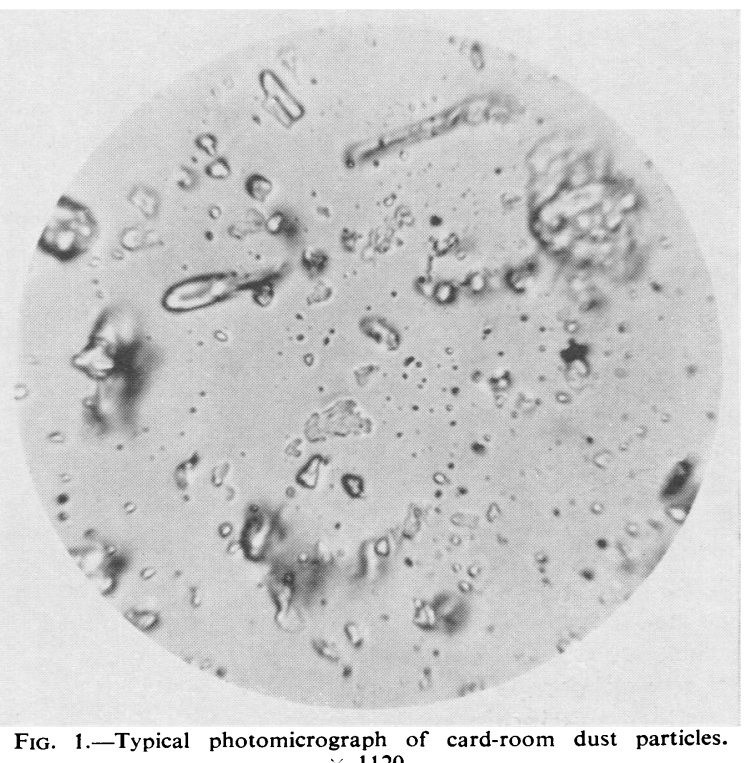
$\times 1120$.

The present paper deals with counts of viable bacteria, as collected in a Bourdillon-type slitsampler on nutrient agar and incubated at $37^{\circ} \mathrm{C}$. (Bourdillon, Lidwell, and Thomas, 1941) ; counts of fine dust particles in the range of 0.5 to $6 \cdot \ell$ in diameter, collected in a thermal precipitator and 
counted under a $2 \mathrm{~mm}$. oil-immersion lens (Green and Watson, 1935); and gravimetric estimations of the total airborne solids collected in small electrostatic precipitators (Drinker, 1932).

Results are reported for the conditions in the card rooms of a group of six cotton spinning mills before and after the introduction of oiling.

\section{Experimental Plan}

Each mill was visited three times: once immediately before oiling was begun, a second time as soon as the oiling equipment had been in operation long enough to ensure stable conditions for the tests, and finally in the following year as nearly as possible on the same dates as at the first visit. The final visit was timed thus in order to avoid a possible seasonal effect in the comparison with the initial visit, and the intermediate visit was included lest drastic changes such as complete alteration in the cotton mixings should take place before the final visit could be made. There were inevitably some changes in the proportions of the various types and grades of cotton in the mixings but, since each mill remained on the same class of work throughout, the same general quality of raw material was maintained as well as supplies allowed. Even the greatest change noted in the cotton used* was not obviously correlated with a corresponding change in the results observed for airborne contamination, for which the other variables in the experiment appeared to be of greater consequence.

Between the intermediate and final visits, however, there was, in general, a change in the crop year of the cottons which may well have affected their bacterial contents even though their commercial grades were unchanged. (This statement is difficult to establish with certainty, and is subject to many minor reservations, but the cottons were traced with the assistance of the Raw Cotton Commission back to their shipments and inferred crop years, so far as the records allow.)

The later visits to any one mill were made to include the same days of the week as the first visit so that any systematic variation throughout the week could, if necessary, be eliminated in the " oiling" comparison.

Since byssinotic subjects experience tightness of the chest and difficulty in breathing more severely on Mondays than on the other days of the week, visits on Mondays were included in the programme at as many mills as possible, in order to give an

\footnotetext{
* This was at Mill D where the mixing was changed from $50 \%$ American and 50\% Brazilian cotton at visit 2, to $100 \%$ American at visit 3. The figures in Table 1 show no sign of having been affected by this change.
}

objective comparison between the mill atmosphere on Mondays and on other working days.

There were fluctuations in the conditions in the mills during the experiment, due to sporadic alterations in the operation of the ventilating systems, to the efficiency with which oiling was maintained, and to the numbers of carding machines in actual operation. These, however, arose from the day-to-day exigencies of production in the mills and were beyond our control. Where possible, steps were taken to avoid taking readings during a prolonged interruption of the normal conditions but, for the most part, such interruptions could be regarded as temporary and random, so that the means taken over the durations of the visits to each mill and over the whole group of mills give a good picture of the overall effect of oiling on the airborne contamination.

Counts of Bacteria and Dust Particles.-The resources available for these two measurements were insufficient to carry out general sampling throughout the room, and observations were therefore confined to a single site in each card room, the identical site being returned to on the later visits ; this was chosen, in each case, to be as near as possible to the centre of the body of carding machines in production. Drifts of ventilating air may invalidate the implied assumption that a site thus chosen is representative of the whole card room, and variations in the counts from mill to mill may therefore be somewhat confused with variations from point to point in each card room. Nevertheless, the numerical results obtained do broadly reflect the subjective impressions of the amount of airborne contamination in each mill.

The visits made before the introduction of oiling had to be restricted to two days at each mill, in order to complete the tests throughout the group of mills in the limited time available before the oiling equipment was installed. Subsequent visits were extended to three days in every case.

Previous experience (Drummond and Hamlin, 1952) had shown that the bacterial counts in cardroom air are very high and that the volumes of air sampled must be kept small to avoid overcrowding the Bourdillon sampler plates. Special alternative slits, narrower than the standard slit, were therefore provided for the sampler, and exposures were reduced to five or 10 seconds ; the sampler turntable rotated once very five seconds. Under these conditions the contamination of plates during handling in the card-room air becomes of unusual importance and the result calculated from a single plate is subject to a large systematic error. By taking a number of plates in rapid succession using different 
volumes of aspirated air, and plotting the observed colony counts against air volumes, however, a straight line plot is obtained of which the slope gives the true count per unit volume, while the negative intercept on the volume axis represents the mean volume of contaminating air (Fig. 2). In the present work, sampler plates were taken in standardized groups of four

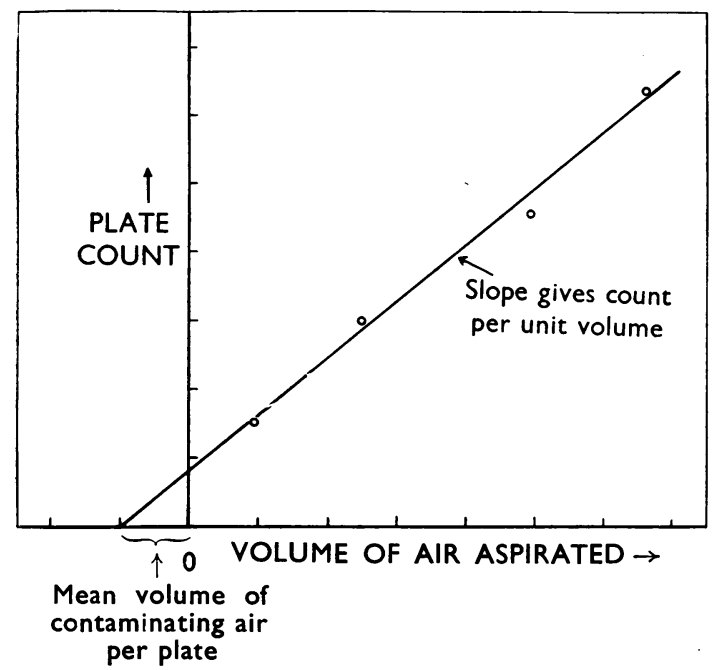

FIG. 2.-Derivation of bacterial count per unit volume from the observed counts in a group of Bourdillon sampler plates, when the contamination during handling in the sampled atmosphere is appreciable.

(The points plotted here are means; results for a single group of four plates show considerably more scatter.)

On the first, or pre-oiling, group of visits, 20 plates a day were taken in five groups, to give two figures for the morning and three for the afternoon on each day ; on the subsequent, post-oiling, visits the plates were increased to 24 per day to give three figures for the morning and three for the afternoon.

The plates were taken with the normal work of the mill going on, though, where possible, exposures were avoided in the heavy dust clouds during stripping of the immediately adjacent cards. In the afternoon no observations of bacteria were made until the machines had been restarted for at least half an hour after the lunch hour break.

For the dust counts it was necessary, in general, to take runs of at least one hour to obtain satisfactory thermal precipitator traces, and this limited the tests to a single run in the morning and two runs in the afternoon on each day ; there were a very few deviations from this routine, morning and afternoon readings always being obtained.

Runs were only taken when normal work was in progress, but they were not interrupted during the stripping of the adjacent cards since the heavy dust cloud persists for only a small fraction of the total time in a one-hour run.

Gravimetric Measurements of Total Airborne Solids. -Since dust deposits are much more quickly assessed by gravimetric methods than by counting, it was practicable to increase the number of days of the visit to each mill and to take six gravimetric samples simultaneously, in pairs, at three sites in each card room. Each precipitator head could, however, only be used for one run per day, since five or six hours were required to give a deposit which was weighable with sufficient accuracy.

The visits before the installation of the oiling equipment were restricted to two days at each mill, as before, but the later visits were extended to four and sometimes five days. The electrostatic precipitators were of the Drinker design (Drinker, 1932), with slight modification of the dimensions, and sampled at the rate of 1 cubic foot per minute. The deposit was collected on filter paper which was weighed before and after the sampling run, having been oven-dried before each weighing.

\section{Results}

From Table 1 it will be seen that, at the time of the first series of visits after the introduction of " oiling", the bacterial concentration had been reduced at five of six mills and that at four of these the reduction was statistically significant at the $5 \%$ level; at the sixth mill there was an unexplained, though significant, increase. The average reduction, over all six mills, was to $70 \%$ of the former count but, owing to the large scatter of the results, combined with the small number of mills visited, the figures do not establish the reduction as significant for the class of mills from which the sample of six was drawn.

The count of fine dust particles, on the other hand, was statistically significantly reduced (at the $5 \%$ level) at all six mills, the new average count being only $40 \%$ of the original. The improvement is better and more consistent than that found with bacteria, and the figures do establish a significant reduction for the whole population of mills.

The gravimetric measurements on the same visits showed some reduction in airborne material at every mill; this reached the $5 \%$ significance level at only three out of the six mills and the average reduction was to $79 \%$, but nevertheless as a whole this indicates a significant effect for mills of this class. This is the figure for the present group of six mills for which parallel results on fine dust and bacteria are available. Over a wider range of mills 
TABLE 1

RESULTS OF COUNTS OF BACTERIA, FINE DUST, AND AIRBORNE SOLIDS AT THREE VISITS

\begin{tabular}{|c|c|c|c|c|c|c|c|c|c|}
\hline \multirow[t]{2}{*}{ Mill } & $\begin{array}{c}\text { Visit* } \\
1: \\
\text { Pre- } \\
\text { oiling }\end{array}$ & $\begin{array}{c}\text { Visit } \\
2: \\
1 \text { st } \\
\text { Post- } \\
\text { oiling }\end{array}$ & $\begin{array}{l}\text { Visit } \\
3: \\
\text { 2nd } \\
\text { Post- } \\
\text { oiling }\end{array}$ & & & & & & \\
\hline & \multicolumn{8}{|c|}{ Bacteria (mean counts per cubic foot) } & \multirow[b]{2}{*}{+} \\
\hline A & 10,000 & 6,900 & 16,500 & 68 & - & 165 & + & 241 & \\
\hline B & 2,900 & 2,200 & 7,200 & 76 & O & 248 & + & 326 & + \\
\hline $\mathrm{C}$ & 14,500 & 3,600 & 6,400 & 25 & - & 44 & - & 180 & + \\
\hline D & 9,400 & 5,800 & 6,000 & 61 & - & 64 & - & 105 & $\mathrm{O}$ \\
\hline $\mathrm{E}$ & 5,200 & 7,400 & 8,500 & 142 & + & 163 & + & 114 & $\mathrm{O}$ \\
\hline$F$ & 6,100 & 3,600 & 5,600 & 60 & - & 92 & $\mathrm{O}$ & 155 & + \\
\hline $\begin{array}{l}\text { Average } \\
\text { standard } \\
\text { errors } \\
\text { of mill } \\
\text { means }\end{array}$ & $12 \%$ & $11 \%$ & $10 \%$ & & & & & & \\
\hline \multicolumn{4}{|c|}{ Crude overall mean percentages } & 70 & $\mathrm{O}$ & 129 & $\mathrm{O}$ & 180 & $\mathrm{O}$ \\
\hline
\end{tabular}

Fine Dust (mean counts per c.cm. of particles between 0.5 and $6 \mu$ diameter)

\begin{tabular}{|c|c|c|c|c|c|c|c|c|c|}
\hline A & 367 & 126 & 221 & 35 & - & 60 & - & 175 & + \\
\hline B & 123 & 49 & 70 & 40 & - & 57 & - & 143 & $\mathrm{O}$ \\
\hline $\mathrm{C}$ & 239 & 63 & 60 & 26 & - & 25 & - & 95 & $\mathrm{O}$ \\
\hline D & 159 & 71 & 73 & 45 & - & 46 & - & 103 & $\mathrm{O}$ \\
\hline$E$ & 171 & 112 & 58 & 65 & - & 34 & - & 52 & - \\
\hline$F$ & 133 & 48 & 54 & 36 & - & 41 & - & 112 & $\mathrm{O}$ \\
\hline $\begin{array}{l}\text { Average } \\
\text { standard } \\
\text { errors } \\
\text { of mill } \\
\text { means }\end{array}$ & $8 \%$ & $15 \%$ & $13 \%$ & & & & & & \\
\hline \multicolumn{4}{|c|}{ Crude overall mean percentages } & 40 & - & 44 & - & 110 & $\mathrm{O}$ \\
\hline
\end{tabular}

Total Airborne Solids (gravimetric load (mg. per cu. m.))

\begin{tabular}{|c|c|c|c|c|c|c|c|c|c|}
\hline A & 5.69 & $5 \cdot 37$ & $6 \cdot 11$ & 94 & o & 107 & $\mathrm{O}$ & 114 & + \\
\hline B & $2 \cdot 34$ & $2 \cdot 16$ & $4 \cdot 20$ & 92 & $\mathrm{O}$ & 179 & + & 194 & + \\
\hline C & 3.96 & 2.39 & 3.03 & 60 & - & 77 & O & 127 & + \\
\hline D & 4.97 & $3 \cdot 54$ & 3.87 & 71 & - & 78 & O & 110 & $\mathrm{O}$ \\
\hline$E$ & 4.47 & 2.74 & 3.89 & 61 & - & 87 & O & 143 & + \\
\hline$F$ & $2 \cdot 27$ & $2 \cdot 20$ & $2 \cdot 71$ & 97 & 0 & 119 & O & 123 & 0 \\
\hline $\begin{array}{l}\text { Average } \\
\text { standard } \\
\text { errors } \\
\text { of mill } \\
\text { means }\end{array}$ & $12 \%$ & $7 \%$ & $6 \%$ & & & & & & \\
\hline \multicolumn{4}{|c|}{ Crude overall mean percentages } & 79 & - & 108 & $\mathbf{O}$ & 135 & + \\
\hline
\end{tabular}

$-=$ percentage statistically significantly (at $5 \%$ level) less than $100 \%$.

$+=$ percentage statistically significantly greater than $100 \%$.

$\mathrm{O}=$ percentage not differing significantly from $100 \%$

* The numbers of observations available from each visit to each mill are rather more variable in the gravimetric investigation than in either of the counting investigations. the gravimetric figures show a rather better average reduction of airborne matter.

In the final group of visits it was found that the improvement in fine dust counts had been maintained but that the gravimetric loads and, more especially, the bacterial counts, showed increases which were statistically significant at most of the mills. Insufficient care in the maintenance of the oiling equipment may be partly responsible for this deterioration at some of the mills, but the changed crop year of the raw cottons themselves could be the reason for a substantial part of the change in the bacterial counts.

Qualitative Changes in the Airborne Load after Oiling.-Since the gravimetric estimation gives a less favourable figure for dust suppression than does the count of fine dust particles, and the reduction in count of fine dust is maintained while the weight of total airborne solids increases under conditions of possibly less careful maintenance of the oiling equipment, it may be concluded that the fine dust is more easily and efficiently suppressed by oil than is the fly. This is as one might expect and is supported by earlier gravimetric observations at this Institute, in which "coarse fly" was distinguished from "fine fly plus dust". Our results, however, show no clear-cut change in the size-frequency distribution within the limited size-range of the optical counts, and we cannot confirm the reduction of median size in this range which the Factory Inspection Department has reported to be a consequence of oiling (Joint Advisory Committee of the Cotton Industry, 1952).

The analysis of the frequency distributions of types of bacteria before and after oiling has not been attempted.

Effects Other than that of "Oiling".--An analysis of variance shows that the differences from one mill to another are statistically highly significant and constitute by far the largest source of variation in the results in all cases. How much of this variation is due to differences between mills and how much to non-uniformity of the airborne load from point to point in a card room cannot, however, be determined from the available data.

It is also found that the concentrations generally vary significantly over the duration of a visit to a mill. The magnitude of this effect seems to be rather greater in the bacterial counts than in the dust counts.

A further possible variation which has been examined is that between Mondays and other days of the week. The results have been separately collected for Mondays and other working days for 
TABLE 2

COMPARISON BETWEEN MONDAYS AND OTHER WORKING DAYS*

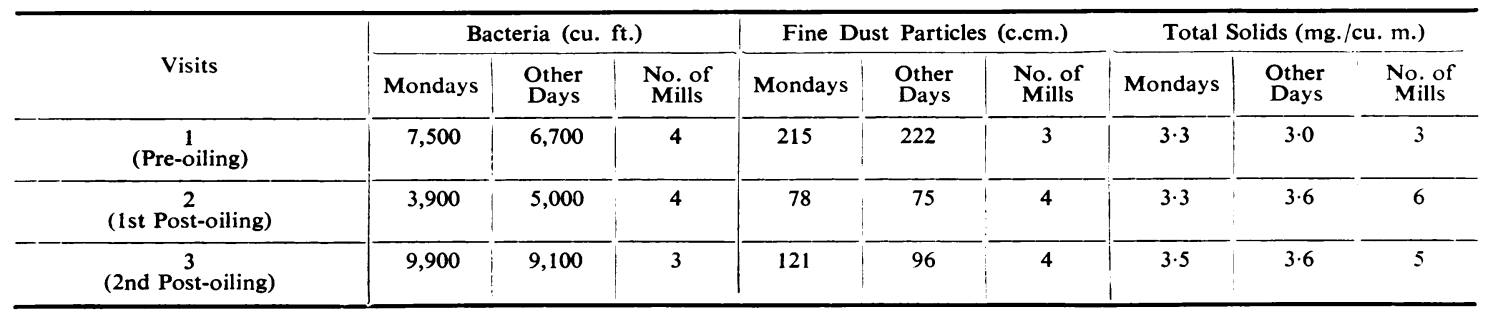

*The figures are means for the groups of mills for which the results allow this comparison to be made. The number of mills in each such group is given in the third column.

None of the differences between Monday and other days, in this table, reaches statistical significance at the $5 \%$ level.

all cases where the figures permit of a comparison, and the means of these are given in Table 2. None of the differences between Mondays and other days is statistically significant and there is no clear tendency for either bacteria or fine dust particles or total airborne solids to be more concentrated on Mondays than at other times; this supports the general belief that the greater pulmonary discomfort felt by affected cotton workers on Mondays is due not to any special condition of the card-room atmosphere on Monday but to the subjects' different reaction to that atmosphere after the week-end break.

\section{Summary}

The airborne dust and bacteria in cotton card rooms have been measured in a group of mills before and after the introduction of equipment for oiling the cotton at the pre-carding stages.

The immediate effect of oiling was to reduce the counts of fine dust particles to $40 \%$, and the counts of viable bacteria to $70 \%$ of their initial levels. The total weight of airborne solids estimated gravimetrically was reduced to $79 \%$ of the previous level.
Further measurements one year later, when a new crop of cotton was coming through the machines showed that, though the improvement in fine dust count had been maintained, the gravimetrically measured solids had increased again, and so, to an even greater extent, had the bacterial count. This deterioration is attributed partly to inadequate maintenance of the oiling equipment and partly to the changed crop-year of the cotton.

Analysis of the figures available showed no significant difference between the concentrations of airborne contaminants on Monday and on any other week-day.

\section{REFERENCES}

Bourdillon, R. B., Lidwell, O. M., and Thomas, J. C. (1941). J. Hyg., Lond., 41, 197.

Collis, E. L. (1909). Annual Report of Chief Inspector of Factories and Workshops for 1908, pp. 203-205. H.M. Stationery Office, London.

Drinker, P. (1932). J. industr. Hyg., 14, 364.

Drummond, D. G., and Hamlin, Mary (1952). British Journal of Industrial Medicine, 9, 309.

Green, H. L., and Watson, H. H. (1935). " Physical Methods for the Estimation of the Dust Hazard in Industry." Spec. Rep. Ser. med. Res. Coun., Lond., No. 199.

Joint Advisory Committee of the Cotton Industry (1952). Dust in Cardrooms: Second interim report, p. 10. H. M. Stationery Office, London.

Paton, H. (1948). Text. Wkly, 42, 1402. 